\title{
Diagnostic Accuracy of Fine-needle Aspiration Cytology of Thyroid Nodules at two tertiary Hospitals in Zambia: a cross-sectional study
}

\author{
Chipaila $J^{1}$, Makupe $A^{1}$, Malyangu $E^{2}$, Maswahu $D^{2}$, Kabwe $J^{3}{ }^{3}$, and Odimba EBFK ${ }^{1}$ \\ 1. Department of Surgery, University Teaching Hospital-Adult, Private Bag RW 1X, Lusaka, Zambia. \\ 2. Department of Pathology, University Teaching Hospital-Adult, Private Bag RW 1X, Lusaka, Zambia. \\ 3. Department of Anesthesiology and Critical care, University Teaching Hospital-Adult, Private Bag RW 1X, \\ Lusaka, Zambia.
}

\begin{abstract}
Address of Correspondence:
Jackson Chipaila; Department of Surgery, University Teaching Hospital-Adult, Private Bag RW 1X, Lusaka, Zambia. Telephone: 260-1-977884771; E-mail: jjchipaila@yahoo.com
\end{abstract}

\begin{abstract}
Introduction: Thyroid nodules are one of the common surgical presentations in Africa and are of great concern because of their potential to be malignant. Zambia is not excluded from these common surgical conditions. However, there are no preoperative cellular or intraoperative tissue diagnoses of the thyroid nodules done before thyroidectomy making it challenging to plan optimal and definitive management. Fine needle aspiration cytology (FNAC) is known to play a pivotal role in the screening and managing thyroid swellings. This study assesses the diagnostic accuracy of FNAC on thyroid nodules in patients at two tertiary hospitals in Zambia to establish a basis of introducing its use in the management of thyroid nodules at the institutions.
\end{abstract}

Objectives: To evaluate the accuracy of FNAC, as compared to histopathology, in the diagnosis of thyroid nodules at University Teaching Hospital (UTH) and Ndola Central Hospital (NCH) in Zambia.

Methods: This was a prospective cross-sectional study conducted in UTHandNCHsurgery department from June 2014 to March 2015. Seventy-three patients, who presented with palpable thyroid nodules and underwent thyroidectomy, were enrolled in the study. The FNAC diagnosis of the patients was compared to the histopathology finding following thyroidectomy.

Results: Females made up the majority of the patients $(\mathrm{n}=67,91.8 \%)$. The ages of the patients ranged from 18 to 78 years. The mean age was 44.3 years, and the peak age of incidence was in the fourth decade. All patients were clinically euthyroid at the time of enrolment. The FNAC findings included 23 cases reported as unsatisfactory (31.5\%); 29 cases benign $(39.7 \%)$; 2 cases atypical $(2.7 \%) ; 6$ cases suspicious $(8.2 \%)$; and 13 cases malignant (17.8\%).Histopathology findings were available from all 73 tissue samples of participants, of which $55(75.3 \%)$ and $18(24.7 \%)$ were reported as benign and malignant respectively. Of the 18 malignant cases identified by histology, the most common cancer was follicular carcinoma $(\mathrm{n}=9,50 \%)$, followed by papillary carcinoma $(n=6,33.3 \%)$ and undifferentiated carcinoma $(\mathrm{n}=3,16.7 \%)$. In this study, FNAC had sensitivity, specificity, negative and positive predictive values, and accuracy of $83.33 \%, 89.09 \%$, 94.23 and $71.42 \%$, and $87.67 \%$ respectively.

Conclusion: In this study, FNAC of thyroid nodules had a high sensitivity, specificity, predictive values and accuracy, and can therefore be recommended to be adopted as a preoperative tool for screening of thyroid nodules.

Keywords: thyroid nodule, fine-needle aspiration cytology, diagnostic accuracy, histopathology.

\section{INTRODUCTION}

A thyroid nodule is a discrete lesion within the thyroid gland that is palpable and/or ultrasonographically distinct from the surrounding thyroid parenchyma 1, 2. Incidentalomas are thyroid nodules that are incidentally found during imaging studies like ultrasound and are not palpable2. By and large, only nodules larger than $1 \mathrm{~cm}$ should be evaluated, because they have the potential to be clinically malignant 2 .

Thyroid nodules are one of the common surgical presentations and are of great concern because of their potential to be malignant3. A study done in Kampala, Uganda, showed that only about $10 \%$ of the thyroid nodules were malignant 4 . Depending on the method of screening, the prevalence of thyroid nodules varies. Using ultrasound, the prevalence was 30 to $50 \%$, while on physical examination, it was only 5 to $7 \% 5$. The prevalence of endemic goitres in Uganda, South Africa and the Democratic Republic of Congo was $60.2 \%$, 
$74.2 \%$ and $65-85 \%$ respectively 6 . In Uganda, $82 \%$ of the goitres were actually nodular4.

Thyroid nodules are equally a common clinical presentation at the University Teaching Hospital (UTH), Lusaka, and Ndola Teaching Hospital (NTH), Ndola, tertiary-level hospitals Zambia. Anecdotal data of operations from 2004 to 2013 at UTH indicated that an average of two thyroidectomies was performed every month, while 2014 data from NTH revealed that an average of twelve thyroidectomies was performed every month. However, none of these thyroidectomies performed had preoperative cellular or intraoperative tissue diagnoses, making it challenging to plan optimal and definitive management.

Fine needle aspiration cytology (FNAC) is known to play a pivotal role in the screening and managing thyroid swellings. FNAC was a safe, sensitive and specific technique in the initial evaluation of thyroid nodules, and a correct cytological diagnosis can be achieved in a majority of cases, thus obviating the need for a second surgical intervention7.

Therefore, before thyroidectomy, FNAC of the thyroid nodules readily gives a cytological diagnosis of the nodules as benign, suspicious or malignant. This is critical because it would allow surgeons to prioritiseprioritise patients and avoid unnecessary operations, which are costly and maybe a source of morbidity and mortality.

This study assesses the diagnostic accuracy of FNAC on thyroid nodules at UTH and NTH to provide a basis for introducing its use in the management of thyroid nodules at the two institutions.

\section{MATERIALS AND METHODS}

This was a prospective cross-sectional study conducted in Surgery Departments at the UTH and NCH in Zambia from June 2014 to March 2015. The sample size of 118 patients was calculated based on the sensitivity and specificity sample size formulae. Convenience sampling was used, with consecutive patients being recruited in order to eliminate bias. The study enrolled 84 participants; however, only 73 were eligible for analysis. Data were collected from the patients with the aid of a data collection sheet. After proper patient counselling, all patients were requested to sign a written informed consent. FNAC was done in theatres by the researcher and two trained assistants after which their attending surgeons did the elective thyroidectomy.
FNAC was done under aseptic conditions. The thyroid nodule was immobilised using the thumb and index finger of the left hand. A 21 or 23 gauge needle on a $10 \mathrm{mls}$ syringe was inserted into the thyroid nodule then a negative pressure was created by pulling the plunger to the $10 \mathrm{mls}$ mark. The needle was then rocked several times gently in the thyroid nodule to obtain as much tissue as possible. Then the aspiration using the $10 \mathrm{ml}$ syringe was terminated when the material became visible in the syringe hub. The needle was then withdrawn, and the pressure was applied over the puncture site to minimise bleeding. The procedure was repeated not less than three times to ensure an adequate amount of tissue was collected. After the procedure, the pressure was applied over the neck for 5 to 10 minutes to ensure haemostasis.

The aspirate was spread onto six slides and spread thinly, and then three slides were air-dried for 5 to 10 minutes, and the other three slides were fixed in alcohol. The slides were then stained with Giemsa, Papanicolaou, and Hematoxylin \& Eosin. After which they were then taken for reporting to a Consultant Pathologist.

The diagnostic value of FNAC was determined by calculating its sensitivity, specificity, positive and negative predictive values, and accuracy. Sensitivity, specificity, predictive value analyses and accuracy were done with the aid of a $2 \times 2$ table. The histopathology results were taken as the gold standard, and the FNAC result that matched with histopathology finding were regarded as true positive.

\section{RESULTS}

The age range was between 18 and 78years, with a mean age of 44.34 years (figure 1). In this study, the participants' sex distribution was 67 females and six males representing $91.8 \%$ and $8.2 \%$ respectively.

The duration of the goitres ranged from 1 to 35 years, with a median of 8 years at presentation to the hospital. Most of the goitres $(84.9 \%)$ were described as slow-growing, and $94.5 \%$ were clinically nodular. The nodular goitres were further classified into solitary (41.1\%) and multinodular $(58.9 \%)$. All 73 participants were clinically euthyroid.

The cytopathology findings (Table 1) on the 73 thyroid FNACs performed during the eight months of the study period included: 23 cases reported as unsatisfactory $(31.5 \%)$; 29 cases reported as benign $(39.7 \%) ; 2$ cases reported as atypical $(2.7 \%) ; 6$ 
cases reported as suspicious (8.2\%), and 13 cases reported as malignant $(17.8 \%)$.

All the 73 participants had a thyroidectomy with subsequent histopathology done. The histopathological findings included (Table 2): Fifty-five (75.3\%) benign and eighteen (24.7\%) malignant. Of the 18 malignant tumours identified, the most common carcinoma was follicular carcinoma $(50 \%)$, followed by papillary carcinoma $(33.3 \%)$ and undifferentiated carcinoma (16.7\%).

Table 3 shows the FNAC diagnosis and their corresponding histopathology diagnosis for all the patients in the study. All 73 FNAC results were used to determine the diagnostic value of FNAC. Three of the 23 FNAC results in the non-diagnostic category, were found to have malignancy on histology and were considered false negative. The 29 that had benign results by FNAC, also had benign histology result thus were considered true negative (TN). Those with atypia of undetermined significance $(\mathrm{n}=2)$ had benign histology results and were considered false positive (FP). Those with suspicious for malignancy $(n=6)$ had carcinomas on histology and were considered true positive (TP). Of the 13 considered malignant on FNAC, 4 had follicular adenoma on histology and were classified as false positive (FP). The remaining 9 had carcinomas on histology and were classified as true positive (TP).

Table 4 shows a $2 \times 2$ table used to calculate FNAC's sensitivity, specificity, positive and negative predictive values.

\begin{tabular}{|l|l|}
\hline Sensitivity : & $\mathrm{TP} / \mathrm{TP}+\mathrm{FN}=15 / 15+3=15 / 18=83.33 \%$ \\
\hline Specificity: & $\mathrm{TN} / \mathrm{TN}+\mathrm{FP}=49 / 49+6=49 / 55=89.09 \%$ \\
\hline $\begin{array}{l}\text { Negative Predictive } \\
\text { Value: }\end{array}$ & $\mathrm{TP} / \mathrm{TP}+\mathrm{FP}=15 / 15+6=15 / 21=71.42 \%$ \\
\hline Accuracy: & $\begin{array}{l}(\mathrm{TN}+\mathrm{TP}) /(\mathrm{TN}+\mathrm{TP}+\mathrm{FN}+\mathrm{FP})=(49+15) / \\
(49+15+3+6)=87.67 \%\end{array}$ \\
\hline
\end{tabular}

Subtotal thyroidectomy was the commonest surgical procedure, accounting for $41.1 \%$, followed by lobectomy $27.4 \%$, total thyroidectomy $16.4 \%$ and near-total thyroidectomy $15.1 \%$ (Table 5). However, out of 18 malignant thyroid carcinomas picked up in this study, only 2 (11.1\%) had undergone total thyroidectomy.

\section{DISCUSSION}

The total number of patients enrolled in this study was 84 although only 73 were eligible for analysis this was because for the other 11 cases $(13.1 \%)$ had either their slides or cytopathology or histopathology results lost.

Most of the patients in the study were females at $91.8 \%(67)$. The males were at $8.2 \%$ (6), giving the female to male ratio of $11.2: 1$. This is in line with literature that thyroid nodules are more common in women8.

The ages of the patients ranged from 18 to 78 years. The mean age was 44.34 years, and the peak age of incidence was in the fourth decade. This is slightly different from a study done by Khageswar Rout et al, in 2011, the peak incidence was noted to be the third decade9.

All patients were clinically euthyroid when they were enrolled into the study. This is because all patients were enrolled at the time when they were prepared for thyroidectomy, and had been stabilised in terms of their thyroid function.

The duration of the patients having thyroid goitres was from 1 to 35 years. This wide range can be attributed to the general population's poor health-seeking behaviour and the difficulties most patients encounter when seeking specialised treatment. The growth of most thyroid goitres was asymptomatic for a long time and did not interfere with the patients' daily chores, except anterior neck swellings. Therefore most patients did not seek medical help until late symptoms arose from compression of either oesophagus or trachea.

This study highlighted the usefulness of FNAC as a preoperative assessment tool in the management of thyroid nodules as recommended by the American Thyroid Association and the National Comprehensive Cancer Network8. Benign was the commonest cytopathological finding in this study and corresponded to other published studies8, 10 .

The non-diagnostic results reported were mainly due to the principal investigator and the two assistants' initial inexperience in the collection and preparation of the FNAC, as it was their first experience in performing this technique. However, the success rate at collecting the tissue specimen improved with time, thereby supporting the premise that FNAC is a technique which is easy to learn. The other contributing causes to having nondiagnostic results could have been sampling error and misinterpretation. Sampling errors could have been mitigated using an ultrasound scan to help locate the nodule and guide aspiration 11 . Thyroid ultrasonography is commonly performed because 
it gives details about the nodule's characteristics and its potential risk of malignancy 12 .

The non-diagnostic result cases were ideally supposed to have been repeated. However, in this study, they were not repeated because of how the research was set up. By the time the FNAC results were available, thyroidectomy would have been performed on the patient.

All the participants in this study underwent a thyroidectomy, with a subsequent histopathology examination of the removed thyroid tissue. In this study, the histopathology findings were that $75.3 \%(55)$ of the thyroid nodules were benign, and $24.7 \%$ (18) were malignant. This is similar to the findings of an earlier published study from Zambia, which reported benign goitres were the commonest thyroid pathology13. Of the 18 malignant tumours identified by histology, the most common carcinoma was follicular carcinoma $(50 \%)$, followed by papillary carcinoma $(33.3 \%)$, and undifferentiated carcinoma $(16.7 \%)$. This is in keeping with a ten-year study on surgically treated thyroid disease patterns in Zambia that showed equally that follicular carcinoma was the commonest thyroid malignancy accounting for $69.2 \%$, followed by papillary carcinoma 14 .

The diagnostic value of FNAC was determined by calculating its sensitivity, specificity, positive and negative predictive values. Sensitivity was defined as the test diagnosed positive for malignancy by FNAC divided by the total positive diagnosis for malignancy as demonstrated by

histopathology after thyroidectomyl. Specificity was defined as the test diagnosed negative for malignancy divided by the total negative diagnosis for malignancy as demonstrated by histopathology after thyroidectomy1. The predictive value was the ratio of the number of times FNAC was correct divided by the total number of either positive or negative FNAC result and was expressed in percentage 1.

The diagnostic value of FNAC of thyroid nodules varies because of many reasons among them is the differences in data analysis of the indeterminate categories (atypical, follicular neoplasm, and suspicious for malignancy) 15 . In this study, these categories were considered positive for malignancy as recommended by most authors8, 11. This increases the sensitivity of the study while reduces its specificity. Out of the 73 cases of FNAC, 21 cases had a cytopathological diagnosis positive for malignancy, of which 15 were true positive, and six were false positive. Thus, FNAC in this study had sensitivity, specificity, positive and negative predictive values, and accuracy of $83.33 \%, 89.09 \%, 71.42$ and $94.23 \%$, and $87.67 \%$ respectively. This is comparable to other studies by Chandanwale and Khairy whose sensitivity and specificity were $90 \%$ and $100 \%$, and $71.4 \%$ and 96.4\% respectively16, 17.

Khairy also indicated that centres that utilised FNAC as a preoperative diagnostic tool reduced the number of unnecessary thyroid operation by $40 \% 17$. The necessity to utilise FNAC in our two institutions has equally been reinforced by the fact that only $11.1 \%$ (2) of patients with malignant thyroid pathologies, in this study, received optimal treatment (total thyroidectomy) for their thyroid cancer. However, all 18 patients have had a form of thyroidectomy. This could have been because the decision regarding the type of surgical procedure to be offered to the individual patient was made without a preoperative diagnosis, and hence not objective.

Following this study's findings, it could be inferred that FNAC of thyroid nodules can be used as a preoperative tool to diagnose thyroid malignancy because it is simple, safe and costeffective. It has the potential to allow appropriate and immediate surgery for patients diagnosed with thyroid malignancy, thereby eliminating unnecessary and inappropriate thyroid operations.

\section{CONCLUSION}

This study demonstrated that the sensitivity, specificity, and predictive value of FNAC of thyroid nodules at the UTH and $\mathrm{NCH}$ is high and has very high potential to be adopted as a preoperative tool for diagnosing thyroid nodules.

The study also demonstrated that benign thyroid pathology is the most common thyroid disease, and follicular carcinoma is the commonest malignancy followed by papillary carcinoma in the patient population referred to the two tertiary hospitals.

\section{ACKNOWLEDGEMENTS}

We would like to acknowledge the mammoth contribution and support of following people: Dr B. Andrews, Prof. B. Vwalika, Dr Y Ahmed, Dr A. Chisakuta, Dr L. Mucheleng'anga, and the histopathology laboratory staff. 


\section{REFERENCES}

1. Song H, Wei C, Li D, Hua K, Song J, Maskey $\mathrm{N}$, et al. Comparison of Fine Needle Aspiration and Fine Needle Nonaspiration Cytology of Thyroid Nodules: A Meta-Analysis. Biomed Res Int [Internet]. 2015 [cited 2019 Dec 6];2015:796120. Available from: http://www. ncbi.nlm.nih.gov/pubmed/26491689

2. Cooper DS, Doherty GM, Haugen BR, Kloos RT, Lee SL, Mandel SJ, et al. Management Guidelines for Patients with Thyroid Nodules and Differentiated Thyroid Cancer: The American Thyroid Association Guidelines Taskforce. Thyroid [Internet]. 2006 Feb [cited 2019 Dec 6];16(2):109-42. Available from: http://www.ncbi.nlm.nih.gov/ pubmed/16420177

3. Mackenzie EJ, Mortimer RH. 6: Thyroid nodules and thyroid cancer. Med J Aust [Internet]. 2004 Mar 1 [cited 2019 Dec 6];180(5):242-7. Available from: http://www. ncbi.nlm.nih.gov/pubmed/14984346

4. Nyonyintono1 J, Fualal J, Wamala D, Galukande M. East and Central African journal of surgery. East Cent African J surgery [Internet]. 2011 [cited 2019 Dec 6];16(2):4654. Available from: http://www.bioline.org. br/request?js11029.

5. McDougall IR. Epidemiology and Etiology of Thyroid Nodules and Thyroid Cancers. In: Thyroid Cancer in Clinical Practice [Internet]. London: Springer London; 2007 [cited 2019 Dec 6]. p. 1-16. Available from: http://link. springer.com/10.1007/978-1-84628-748-0_1

6. Algebra AO, Kuku SF. Epidemiology of thyroid diseases in Africa. Indian J Endocrinol Metab [Internet]. 2011 Jul [cited 2019 Dec 6];15(Suppl 2): S82-8. Available from: http:// www.ncbi.nlm.nih.gov/pubmed/21966659

7. Muhammad T, Iqbal M. FNAC Of Thyroid Nodule; Diagnostic Accuracy Of Fine Needle Aspiration Cytology (FNAC). Prof Med J [Internet]. 2010 [cited 2019 Dec 6];17(4):58997. Available from: https://www.researchgate. net/publication/49615966_FNAC_OF_ Thyroid_nodule_diagnostic_accuracy_ of_fine_needle_aspiration_cytology_fnac/ citation/download.
8. Yang J, Schnadig V, Logrono R, Wasserman PG. Fine-needle aspiration of thyroid nodules: A study of 4703 patients with histologic and clinical correlations. Cancer [Internet]. 2007 Aug 6 [cited 2019 Dec 6];111(5):306-15. Available from: http://www.ncbi.nlm.nih. gov/pubmed/17680588.

9. Route K, Ray CS, Behera SK, Biswal R. A Comparative Study of FNAC and Histopathology of Thyroid Swellings. Indian J Otolaryngol Head Neck Surg [Internet]. 2011 Oct [cited 2019 Dec 6];63(4):370-2. Available from: http://www.ncbi.nlm.nih. gov/pubmed/23024944.

10. Wu HH-J, Jones JN, Osman J. Fine-needle aspiration cytology of the thyroid: Ten years experience in a community teaching hospital. Diagn Cytopathol [Internet]. 2006 Feb [cited 2019 Dec 6];34(2):93-6. Available from: http://www.ncbi.nlm.nih. gov/pubmed/16514671.

11. Wang D, Fu H-J, Xu H-X, Guo L-H, Li X-L, $\mathrm{He}$ Y-P, et al. Comparison of fine-needle aspiration and non-aspiration cytology for diagnosis of thyroid nodules: A prospective, randomised, and controlled trial. Clin Hemorheol Microcirc [Internet]. 2017 May 5 [cited 2019 Dec 6];66(1):67-81. Available from: http://www.ncbi.nlm.nih.gov/ pubmed/28128748.

12. Mehanna HM, Jain A, Morton RP, Watkinson $\mathrm{J}$, Shaha A. Investigating the thyroid nodule. BMJ [Internet]. 2009 Mar 13 [cited 2019 Dec 6];338:b733. Available from: http://www. ncbi.nlm.nih.gov/pubmed/19286747.

13. Desai G, Islam R. The changing pattern of surgical pathology of the thyroid gland in Zambia. Cent Afr J Med [Internet]. 1992 Jun 1 [cited 2019 Dec 6];38(6):240-2. Available from: https:// journals.co.za/ content/ CAJM/38/6/AJA00089176_700

14. Mirzakarimov F, Odimba B, Tembo P. Patterns of Surgically Treated Thyroid Disease in Lusaka, Zambia. Med J Zambia [Internet]. [cited 2019 Dec 6];39(4):7-11. Available from: https://www.ajol.info/index. php/mjz/article/view/110599. 
15. Alshaikh S, Harb Z, Aljufairi E, Almahari SA. Classification of thyroid fine-needle aspiration cytology into Bethesda categories: An institutional experience and review of the literature. Cytojournal [Internet]. 2018 [cited 2019 Dec 7];15:4. Available from: http:// www.ncbi.nlm.nih.gov/pubmed/29531571

16. Chandanwale $\mathrm{S}$, Singh $\mathrm{N}$, Kumar $\mathrm{H}$. Clinicopathological correlation of thyroid nodules. Int J Pharm Biomed Sci. 2012;3:97-102.
17. Khairy GEA, Murshid KR. Role of fineneedle aspiration biopsy in the management of thyroid nodules. East Afr Med J [Internet]. 2001 Aug 1 [cited 2019 Dec 6];78(8):40810. Available from: http://www.ncbi.nlm.nih. gov/pubmed/11921562 


\section{FIGURES AND TABLES}

Figure 1: Age distribution of the study.

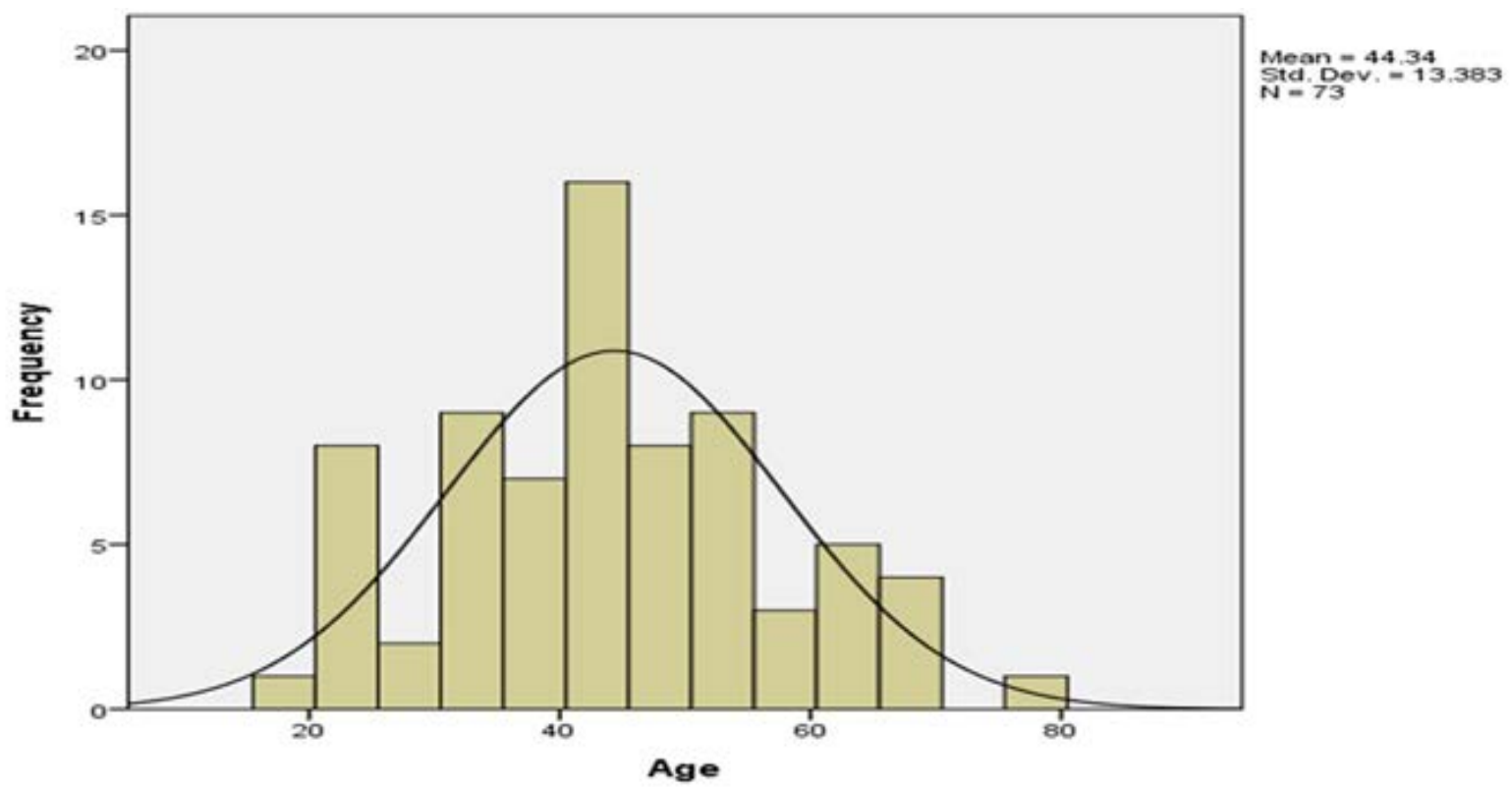

Table 1: Cytopathology findings

\begin{tabular}{|l|c|r|}
\hline & n & \multicolumn{1}{|c|}{ \% } \\
\hline Non-Diagnostic & 23 & 31.5 \\
\hline Benign & 29 & 39.7 \\
\hline Atypia Undetermined Significance & 2 & 2.7 \\
\hline Suspicious for Malignancy & 6 & 8.2 \\
\hline Malignant & 13 & 17.8 \\
\hline Total & 73 & 100 \\
\hline
\end{tabular}

Table 2: Histopathology findings

\begin{tabular}{|c|c|c|}
\hline$n=73$ & $\mathbf{n}$ & $\%$ \\
\hline Malignant & 18 & 24.7 \\
\hline Benign & 55 & 75.3 \\
\hline \multicolumn{3}{|l|}{ Benign } \\
\hline Follicular Adenoma & 6 & 10.9 \\
\hline Others & 49 & 89.1 \\
\hline \multicolumn{3}{|l|}{ Malignant } \\
\hline Follicular Carcinoma & 9 & 50.0 \\
\hline Papillary Carcinoma & 6 & 33.3 \\
\hline Undifferentiated Carcinoma & 3 & 16.7 \\
\hline
\end{tabular}


Table 3: FNAC-Histopathology

\begin{tabular}{|c|c|c|}
\hline FNAC & n $\quad(\%)$ & Histopathology \\
\hline Non Diagnostic & $23 \quad(31)$ & $\begin{array}{lcc}\text { Other Benign } & 18(24)(\mathrm{TN}) \\
\text { Follicular adenoma } & 2 & (3)(\mathrm{TN}) \\
\text { Follicular carcinoma } & 2 & (3)(\mathrm{FN}) \\
\text { Papillary carcinoma } & 1 & (1)(\mathrm{FN})\end{array}$ \\
\hline Benign & $29(40)$ & Other Benign \\
\hline Atypia Undetermined Significance & (3) & Other Benign \\
\hline Suspicious for Malignancy & $6 \quad(8)$ & $\begin{array}{cc}\text { Follicular carcinoma } & 4(6)(\mathrm{TP}) \\
\text { Papillary carcinoma } & 1(1)(\mathrm{TP}) \\
\text { Anaplastic carcinoma } & 1(1)(\mathrm{TP})\end{array}$ \\
\hline Malignant & $13(18)$ & $\begin{array}{ll}\text { Follicular adenoma } & 4(6)(\mathrm{FP}) \\
\text { Follicular carcinoma } & 3(3)(\mathrm{TP}) \\
\text { Papillary carcinoma } & 4(6)(\mathrm{TP}) \\
\text { Anaplastic carcinoma } & 2(3)(\mathrm{TP})\end{array}$ \\
\hline Total & $73(100 \%)$ & $73(100 \%)$ \\
\hline
\end{tabular}

Table 4: The 2X2 Table

\begin{tabular}{|l|c|c|}
\hline & \multicolumn{2}{|c|}{ Histopathology } \\
\hline FNAC results & Malignancy & No Malignancy \\
\hline Positive & TP & FP \\
\hline Negative & FN & TN \\
\hline
\end{tabular}

\begin{tabular}{|l|c|c|c|}
\hline \multirow{2}{*}{ FNAC Results } & \multicolumn{2}{|c|}{ Histopathology Results } & \multirow{2}{*}{ Total } \\
\cline { 2 - 3 } & Malignancy & No Malignancy & $\mathbf{2 1}$ \\
\hline Malignancy & 15 & 6 & $\mathbf{5 2}$ \\
\hline No Malignancy & 3 & 49 & $\mathbf{7 3}$ \\
\hline Total & $\mathbf{1 8}$ & $\mathbf{5 5}$ & \\
\hline
\end{tabular}

Table 5:Surgical procedures

\begin{tabular}{|l|c|ccc|}
\hline & n & \% & Malignant & Benign \\
\hline Lobectomy/hemithyroidectomy & 20 & 27.4 & 2 & 18 \\
\hline Subtotal Thyroidectomy & 30 & 41.1 & 10 & 20 \\
\hline Near-Total Thyroidectomy & 11 & 15.1 & 4 & 7 \\
\hline Total Thyroidectomy & 12 & 16.4 & 2 & 10 \\
\hline Totals & $\mathbf{7 3}$ & $\mathbf{1 0 0} \%$ & $\mathbf{1 8}$ & $\mathbf{5 5}$ \\
\hline
\end{tabular}

